\title{
$\mu$-Phenolato- $\mu$-acetato-bridged Dinuclear Copper(II) Complex with Dinucleating Schiff-base Ligand Having Three Phenolate Groups
}

\author{
Masahiro MikuriYa, ${ }^{\dagger}$ Yuya SATo, and Daisuke Yoshioka \\ Department of Applied Chemistry for Environment and Research Center for Coordination Molecule-based Devices, \\ School of Science and Technology, Kwansei Gakuin University, 2-1 Gakuen, Sanda 669-1337, Japan
}

\begin{abstract}
The $\mu$-phenolato- $\mu$-acetato-bridged dinuclear copper(II) complex with 2-(5-chloro-2-hydroxyphenyl)-1,3-bis(2-(5-chloro2-hydroxybenzylideneamino)ethyl)imidazolidine $\left(\mathrm{H}_{3} \mathrm{~L}\right),\left[\mathrm{Cu}_{2}(\mathrm{~L})\left(\mu-\mathrm{CH}_{3} \mathrm{CO}_{2}\right)\right]$, was synthesized. The crystal structure was determined by the single-crystal X-ray diffraction method at $293 \mathrm{~K}$. The complex crystallized as $\left[\mathrm{Cu}_{2}(\mathrm{~L})(\mu-\right.$ $\left.\left.\mathrm{CH}_{3} \mathrm{CO}_{2}\right)\right] \cdot \mathrm{CH}_{3} \mathrm{CN} \cdot \mathrm{H}_{2} \mathrm{O}$ in the monoclinic space group $P 2_{1} / c$ with $a=9.088(6), b=13.296(9), c=29.20(2) \AA, \beta=$ $95.131(13)^{\circ}, V=3514(4) \AA^{3}, D_{\text {calcd }}=1.520 \mathrm{~g} / \mathrm{cm}^{3}, Z=4$. The $R 1[I>2 \sigma(I)]$ and $w R 2$ (all data) values are 0.0512 and 0.1282 , respectively, for all 8308 independent reflections. The two copper(II) atoms are bridged by phenolato-oxygen of $\mathrm{L}^{3-}$ and $\mu$-acetato, where each copper(II) atom is further coordinated by phenolato-oxygen, imino- and imidazolidinenitrogen atoms of $\mathrm{L}^{3-}$ in a meridional fashion to form a square-pyramidal geometry. The temperature dependence of the magnetic susceptibilities showed a ferromagnetic interaction with $J=+4.3 \mathrm{~cm}^{-1}$ between the two copper(II) atoms.
\end{abstract}

(Received June 19, 2018; Accepted July 21, 2018; Published on web October 10, 2018)

Schiff-base ligand, 2-(5-chloro-2-hydroxyphenyl)-1,3-bis(2-(5chloro-2-hydroxybenzylideneamino)ethyl)imidazolidine $\left(\mathrm{H}_{3} \mathrm{~L}\right)$ is an interesting dinucleating ligand, because it has three phenolate groups within the imdazolidine ligand and gives unique dinuclear lanthanide complexes. ${ }^{1}$ So far, some dinuclear metal complexes with related Schiff-base ligands have been reported..$^{2-5}$ We have engaged in synthetic studies on dinuclear copper(II) complexes with Schiff-base ligands. ${ }^{6-8}$ In this study, we isolated a dinuclear copper(II) complex with $\mathrm{L}^{3-}$, and determined the crystal structure of this complex, which has not yet been reported, as shown in Fig. 1. This paper describes the crystal structure of $\left[\mathrm{Cu}_{2}(\mathrm{~L})\left(\mu-\mathrm{CH}_{3} \mathrm{CO}_{2}\right)\right] \cdot \mathrm{CH}_{3} \mathrm{CN} \cdot \mathrm{H}_{2} \mathrm{O}$. The synthetic method and the magnetic property are also described.

$\mathrm{H}_{3} \mathrm{~L}$ was synthesized by the following procedure with some modification of the literature method. ${ }^{2,3}$ A solution of $0.213 \mathrm{~g}$ $(1.46 \mathrm{mmol})$ of triethylenetetramine in $8 \mathrm{~cm}^{3}$ of ethanol was added to a solution of $0.700 \mathrm{~g} \quad(4.47 \mathrm{mmol})$ of 5-chlorosalicylaldehyde in $8 \mathrm{~cm}^{3}$ of ethanol. The reaction

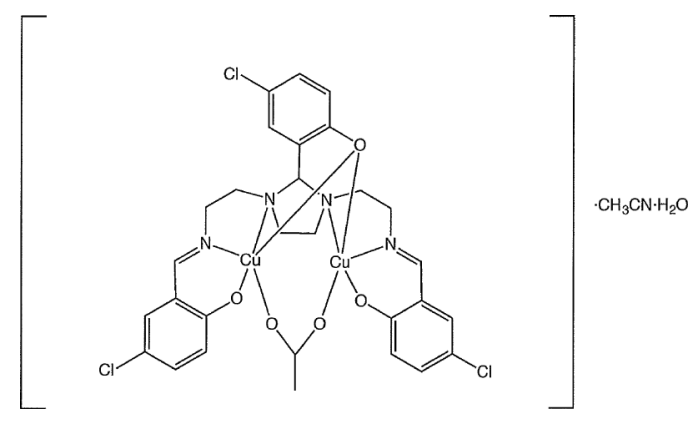

Fig. 1 Chemical structure of the title compound.

† To whom correspondence should be addressed.

E-mail: junpei@kwansei.ac.jp mixture was stirred and heated for $1 \mathrm{~h}$ to give a yellow precipitate. The precipitate was isolated by filtration and washed with ethanol and dried at room tempereature, yielding $0.774 \mathrm{~g}$ (94.4\%). Anal. Found: C, 57.83; H, 5.06; N, 10.29\%. Calcd for $\mathrm{C}_{27} \mathrm{H}_{27} \mathrm{Cl}_{3} \mathrm{~N}_{4} \mathrm{O}_{3}: \mathrm{C}, 57.71 ; \mathrm{H}, 4.84 ; \mathrm{N}, 9.97 \%$. IR $\left(\mathrm{KBr}, \mathrm{cm}^{-1}\right): v(\mathrm{C}=\mathrm{N}) 1633$.

$\left[\mathrm{Cu}_{2}(\mathrm{~L})\left(\mu-\mathrm{CH}_{3} \mathrm{CO}_{2}\right)\right]$. To an acetonitrile solution $\left(10 \mathrm{~cm}^{3}\right)$ of $\mathrm{H}_{3} \mathrm{~L}$ (54.0 mg, $0.0961 \mathrm{mmol}$ ) was added an acetonitrile solution $\left(5 \mathrm{~cm}^{3}\right)$ of copper(II) acetate $(35.8 \mathrm{mg}, 0.197 \mathrm{mmol})$; the mixed solution was then and stirred for $1 \mathrm{~h}$. The resulting solution was filtered and the filtrate was left standing at room temperature for several days to give green crystals. The crystals were collected. Yield, $52.8 \mathrm{mg}\left(68.8 \%\right.$ based on $\left.\mathrm{H}_{3} \mathrm{~L}\right)$. Anal. Found: C, 43.32; $\mathrm{H}, 3.81 ; \mathrm{N}, 6.92 \%$. Calcd for $\mathrm{C}_{29} \mathrm{H}_{33} \mathrm{Cl}_{3} \mathrm{Cu}_{2} \mathrm{~N}_{4} \mathrm{O}_{8}=\left[\mathrm{Cu}_{2}(\mathrm{~L})(\mu-\right.$ $\left.\left.\mathrm{CH}_{3} \mathrm{CO}_{2}\right)\right] \cdot 3 \mathrm{H}_{2} \mathrm{O}: \mathrm{C}, 43.59 ; \mathrm{H}, 4.16 ; \mathrm{N}, 7.01 \%$. IR $\left(\mathrm{KBr}, \mathrm{cm}^{-1}\right)$ : $v(\mathrm{C}=\mathrm{N}) \quad 1645, \quad v_{\mathrm{as}}\left(\mathrm{COO}^{-}\right) \quad 1574, \quad v_{\mathrm{s}}\left(\mathrm{COO}^{-}\right)$1461. Diffused reflectance spectra, $\lambda_{\max }: 242,386,718,1000 \mathrm{sh} \mathrm{nm}$. Absorption spectra (in methanol), $\lambda_{\max }$ : $384 \mathrm{~nm}\left(\varepsilon=9260 \mathrm{M}^{-1} \mathrm{~cm}^{-1}\right.$, CT band (phenolate $(\mathrm{O}) \rightarrow \mathrm{Cu})),{ }^{6,7} 652 \mathrm{~nm} \quad\left(\varepsilon=400 \mathrm{M}^{-1} \mathrm{~cm}^{-1}\right.$, d-d band). ${ }^{7}$

A preliminary examination was made, and data were collected on a Bruker CCD X-ray diffractometer (SMART APEX) using graphite-monochromated Mo- $K \alpha$ radiation. Crystal data and details concerning the data collection are given in Table 1 . The structure was solved by an intrinsic phasing method and refined by full-matrix least-squares methods. The hydrogen atoms, except for the water molecule, were inserted at their calculated positions, and fixed there. All of the calculations were carried out on a Windows 7 Core i7 computer utilizing SHELXT-2014/4 and SHELXL-2014/7.9 Crystallographic data have been deposited with Cambridge Crystallographic Data Centre (Deposit numbers CCDC-1849887). Copies of the data can be obtained free of charge via http://www.ccdc.cam.ac.uk/conts/ retrieving.html (or from the Cambridge Crystallographic Data Centre, 12, Union Road, Cambridge, CB2 1EZ, UK; Fax, +44 1223 336033; e-mail, deposit@ccdc.cam.ac.uk). 
Table 1 Crystal and experimental data
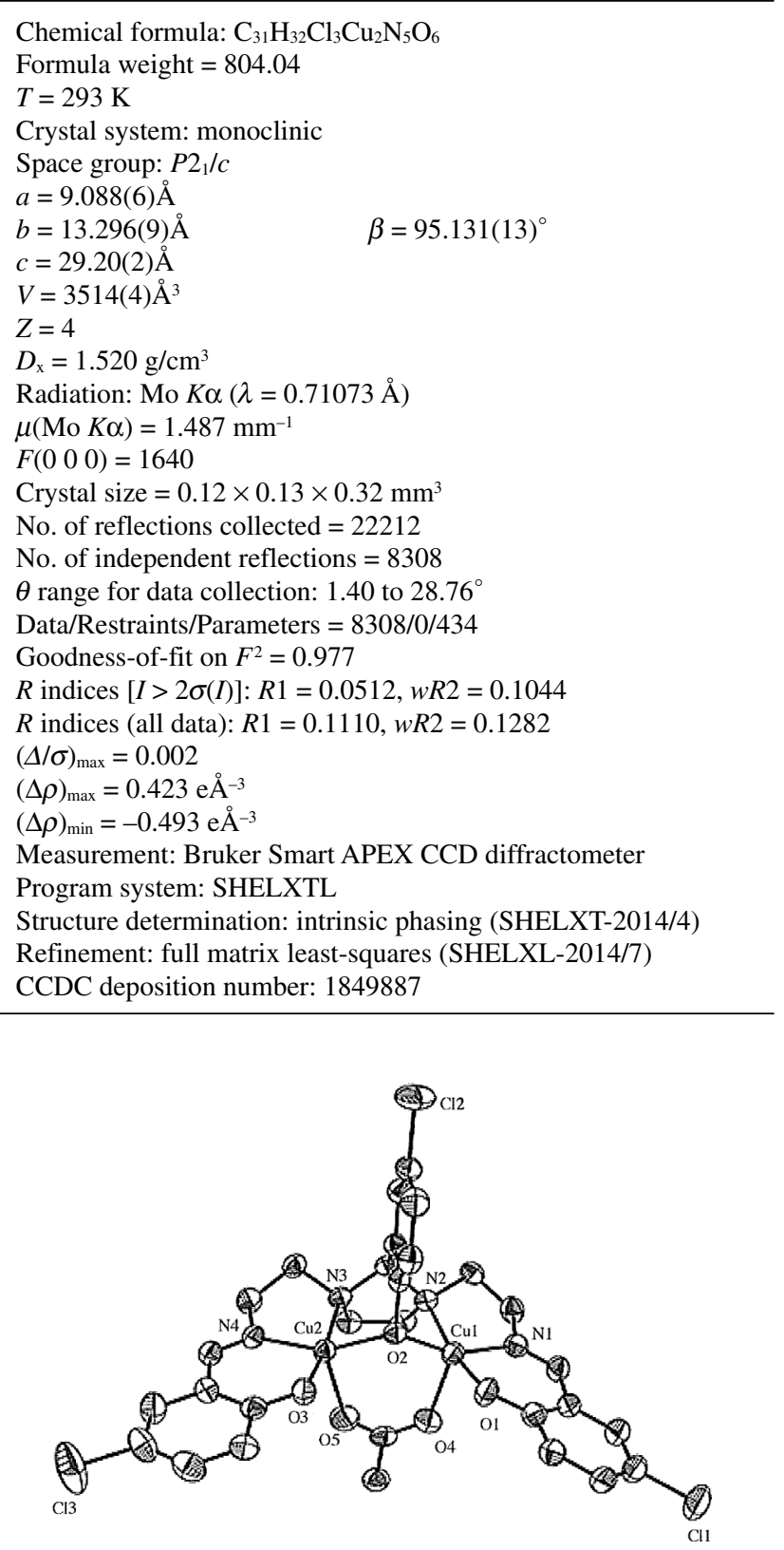

Fig. 2 ORTEP drawing of $\left[\mathrm{Cu}_{2}(\mathrm{~L})\left(\mu-\mathrm{CH}_{3} \mathrm{CO}_{2}\right)\right]$, showing the thermal ellipsoids at the $50 \%$ probability level. Hydrogen atoms are omitted for clarity.

The asymmetric unit consists of one dinuclear molecule $\left[\mathrm{Cu}_{2}(\mathrm{~L})\left(\mu-\mathrm{CH}_{3} \mathrm{CO}_{2}\right)\right]$, one acetonitrile, and one water molecule. The dinuclear molecule was drawn by the ORTEP program in Fig. 2. In the dinuclear molecule, the two copper(II) atoms are bridged by a phenolato-oxygen of $\mathrm{L}^{3-}$ and $\mu$-acetato, where each copper(II) atom is further coordinated by phenolato-oxygen, imino- and imidazolidine-nitrogen atoms of $\mathrm{L}^{3-}$ in a meridional fashion to form a five-coordinate geometry. The $\tau$ values $^{10}$ of the $\mathrm{Cu} 1$ and $\mathrm{Cu} 2$ atoms are 0.177 and 0.233 , respectively, showing distorted square-pyramidal geometries. It is to be noted that the acetate ion bridges the two copper atoms in a synsyn mode, ${ }^{11}$ giving a comparatively long $\mathrm{Cu} 1 \cdots \mathrm{Cu} 2$ distance of $3.328(2) \AA$ (Table 2). In the crystal, water molecule (O6) are hydrogen-bonded to the phenolato-oxygen atoms $(\mathrm{O} 1, \mathrm{O} 2$, and
Table 2 Selected bond distances $(\AA)$ and angles $\left({ }^{\circ}\right)$

\begin{tabular}{lccl}
\hline $\mathrm{Cu} 1 \cdots \mathrm{Cu} 2$ & $3.328(2)$ & $\mathrm{Cu} 2-\mathrm{O} 2$ & $1.993(3)$ \\
$\mathrm{Cu} 1-\mathrm{O} 1$ & $1.930(3)$ & $\mathrm{Cu} 2-\mathrm{O} 3$ & $1.944(3)$ \\
$\mathrm{Cu} 1-\mathrm{O} 2$ & $1.980(3)$ & $\mathrm{Cu} 2-\mathrm{O} 5$ & $2.150(3)$ \\
$\mathrm{Cu} 1-\mathrm{O} 4$ & $2.179(3)$ & $\mathrm{Cu} 2-\mathrm{N} 3$ & $2.116(3)$ \\
$\mathrm{Cu} 1-\mathrm{N} 1$ & $1.955(3)$ & $\mathrm{Cu} 2-\mathrm{N} 4$ & $1.955(3)$ \\
$\mathrm{Cu} 1-\mathrm{N} 2$ & $2.140(3)$ & & \\
$\mathrm{Cu} 1-\mathrm{O} 2-\mathrm{Cu} 2$ & $113.81(13)$ & & \\
\hline
\end{tabular}

Table 3 Hydrogen-bonding geometry $\left(\AA,^{\circ}\right)$

\begin{tabular}{|c|c|c|c|c|}
\hline D-H...A & D-H $(\AA)$ & H...A (A) & D...A $(\AA)$ & $\mathrm{D}-\mathrm{H} \cdots \mathrm{A}\left({ }^{\circ}\right)$ \\
\hline O6-H6A -.O1 & 0.666 & 2.299 & 2.926 & 157.95 \\
\hline O6-H6B-..O2 & 0.711 & 2.635 & 2.971 & 111.58 \\
\hline O6-H6B-..O3 & 0.711 & 2.202 & 2.905 & 170.74 \\
\hline
\end{tabular}

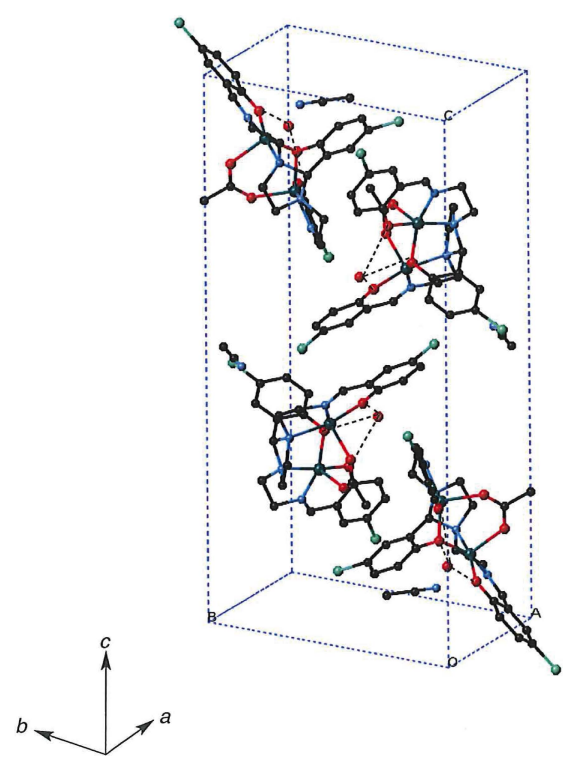

Fig. 3 Packing diagram of the title compound. Hydrogen atoms are omitted for clarity. Dashed lines show hydrogen bonds between the phenolato-oxygen atoms of the dinuclear complex and water molecule.

O3) of $\mathrm{L}^{3-}$, as shown in Table 3 (Fig. 3). The coordination geometries around the copper atoms and the molecular structure found in this study are similar to those of the dinuclear copper(II) complex with the bromo-derivative of the related Schiff-base ligands, although the crystal structure is different from the present one. 5

The diffused reflectance spectrum of the complex showed a CT band at $386 \mathrm{~nm}$ and a broad d-d band $718 \mathrm{~nm}$ with shoulder around $1000 \mathrm{~nm}$. The $\mathrm{d}-\mathrm{d}$ band feature is in agreement with the square-pyramidal geometry around the copper(II) ions. ${ }^{12}$ The absorption spectrum confirmed the assignment of the spectra, although the shoulder around $1000 \mathrm{~nm}$ could not be detected. A magnetic susceptibility measurement was performed with a Quantum Design SQUID susceptometer in the temperature range of $4.5-300 \mathrm{~K}$. The magnetic moment per copper(II) atom is $2.01 \mu_{\mathrm{B}}$ at $300 \mathrm{~K}$. This value is larger than the spin-only value of copper(II) $\left(1.73 \mu_{\mathrm{B}}, S=1 / 2\right)$. As shown in Fig. 4 , the moment takes an almost constant value until $60 \mathrm{~K}$ with lowering of the temperature, and then increases, reaching a maximum value of $2.16 \mu_{\mathrm{B}}$ at $4.5 \mathrm{~K}$. The magnetic data were analyzed by the Bleaney-Bowers equation (1) based on a consideration for 


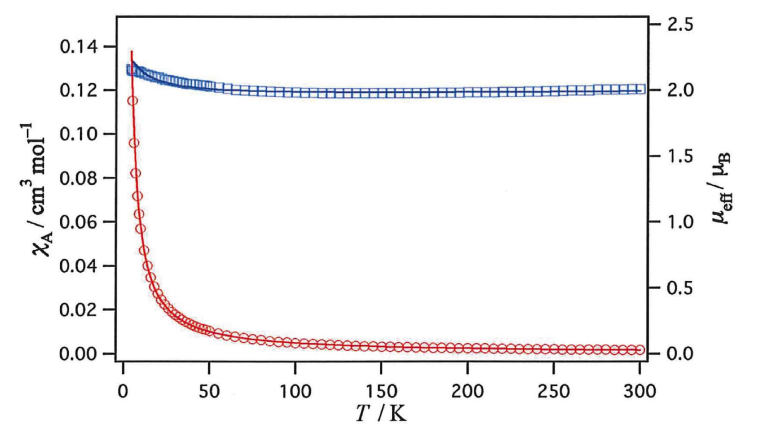

Fig. 4 Temperature dependence of the magnetic susceptibilities (red circle), magnetic moment (blue square), and the fitting curves with the parameters in the text of the title compound.

the exchange interaction $(2 J)$ and temperature independent paramagnetism (tip) of the copper(II) ions: ${ }^{13}$

$$
\chi_{\mathrm{A}}=\left(N g^{2} \beta^{2} / 3 k T\right)[1+1 / 3 \exp (-2 J / k T)]^{-1}+t i p
$$

The best fitting afforded the parameters $J=+4.3 \mathrm{~cm}^{-1}, g=2.25$, and tip $=60 \times 10^{-6} \mathrm{~cm}^{3} \mathrm{~mol}^{-1}$. The magnetic property is also similar to that of the dinuclear copper(II) complex with the bromo-derivative of the related Schiff-base ligands. ${ }^{5}$

\section{Acknowledgements}

The present work was partially supported by Grants-in-Aid for Scientific Research No. 17K05820 from the Ministry of
Education, Culture, Sports, Science and Technology and the MEXT-Supported Program for the Strategic Research Foundation at Private Universities, 2010 - 2014.

\section{References}

1. L. Zhang, F. Jiang, and Y. Zhou, J. Coord. Chem., 2009, 62, 1476.

2. T. Isobe, S. Kida, and S. Misumi, Bull. Chem. Soc. Jpn., 1967, 40, 1862.

3. L.-W. Yang, S. Liu, E. Wong, S. J. Rettig, and C. Orvig, Inorg. Chem., 1995, 34, 2164.

4. A. R. Paital, M. Sarkar, M. Mikuriya, and D. Ray, Eur. J. Inorg. Chem., 2007, 4762.

5. M. Fondo, N. Ocampo, A. M. Garcia-Deibe, M. Corbella, M. R. Bermeijo, and J. Sanmartin, Dalton Trans., 2005, 3785 .

6. S. Wada, K. Saka, D. Yoshioka, and M. Mikuriya, Bull. Chem. Soc. Jpn., 2010, 83, 364.

7. Y. Kakuta, N. Masuda, M. Kurushima, T. Hashimoto, D. Yoshioka, H. Sakiyama, Y. Hiraoka, M. Handa, and M. Mikuriya, Chem. Papers, 2014, 68, 923.

8. M. Mikuriya, M. Hara, D. Yoshioka, and R. Mitsuhashi, X-ray Struct. Anal. Online, 2017, 33, 67.

9. G. M. Sheldrick, Acta Cryst., 2015, C71, 3.

10. A. W. Addison, T. N. Rao, J. Reedijk, J. van Rijn, and G. C. Verschoor, J. Chem. Soc., Dalton Trans., 1984, 1349.

11. M. Mikuriya, Bull. Jpn. Soc. Coord. Chem., 2008, 52, 17.

12. Y. Murakami and K. Sakata, "Kireto Kagaku", ed. K. Ueno, 1976, Vol. 1, Chap. 2, Nankodo, Tokyo.

13. B. Bleaney and K. D. Bowers, Proc. R. Soc., London, Ser. A, 1952, 214, 451 . 